\title{
The Effect of Fins on the Performance of the Plate Heat Recovery Ventilator
}

\author{
Braihan Abdulwadood Salman*1, Saadoon Fahad Albahadili ${ }^{2}$, Raed Sabri ${ }^{3}$ \\ \{parehan.abdulwadood@stu.edu.iq ${ }^{1}$, s.albahadili@stu.edu.iq ${ }^{2}$, read.hameed@stu.edu.iq ${ }^{3}$ \} \\ Basra Engineering Technical College, Southern Technical University of Basra, Iraq ${ }^{1}{ }^{\prime}{ }^{\prime} 3$
}

\begin{abstract}
The present work focuses on modifying an existed commercial heat recovery ventilator unit. The heat exchanger (the core) of this unit is a fixed plate type operating in a crossflow arrangement without fins. The theoretical analysis is performed to investigate the effect of adding a suitable number of fins to the core in two conditions. These conditions are to investigate the effect of adding fins on the performance of the ventilation unit and the possibility of reducing the core size maintaining the original performance, provided that the added fins do not lead to exceeding the permissible pressure drop of 450 $\mathrm{Pa}$ at full capacity of $1000 \mathrm{~m}^{3} / \mathrm{h}$ air flow rate. The obtained results indicate that adding fins up to 144 fins per meter makes the heat recovery ventilator has its highest performance with an increase in effectiveness by $33.3 \%$. The lowest volume that can be obtained without compromising the performance of the exchanger is $37 \%$ of the original volume by adding 120 fins $/ \mathrm{m}$.
\end{abstract}

Keywords: Heat Recovery Ventilator, Plate Heat Exchanger, Energy Saving.

\section{Introduction}

Mechanical ventilation is used to continually provide fresh air while recovering thermal energy [1]. Mainly, compact heat recovery ventilator (HRV) is adopted for better air distribution [2]. It consists of a heat exchanger that transfers heat between the hot fresh air with stale room air that has been thermally pre-treated but carries pollutants and needs to be disposed of. The plate heat exchanger as shown in Fig 1, represents the core of the HRV unit. It is constructed from several Aluminum layers or parting plates. The plates serve as the primary surface for heat transfer. They are stacked on each other, separated by spaces, to form two sets of passages through which fresh air and indoor air alternately flow and exchange heat due to temperature differences without mixing.

Among the many compact heat exchangers, the finned plate heat exchangers have their superior performance. They are distinguished by high efficiency, smaller size, low weight and reasonable cost [3]. The sensible effectiveness is close to 66\% [4].

The most two important factors that affecting the effectiveness of heat exchangers are the heat transfer surface area and the convective heat transfer coefficient. Note that air is one of the lowlevel fluids in the values of the heat transfer coefficient. To compensate for this factor secondary surface areas like fins are used.

One of the important strategies in energy sustainability is to recover heat lost due to ventilation as efficiently as possible by using heat recovery ventilators. The benefit of the energy recovery ventilator was summarized by, reducing HVAC energy consumption, reducing peak demand, 
improving humidity control, and providing appropriate ventilation. The magnitude of the benefits varies depending on climate [5]. The main parameters that affecting the HRV performance are the construction parameters and the operating parameters [6].

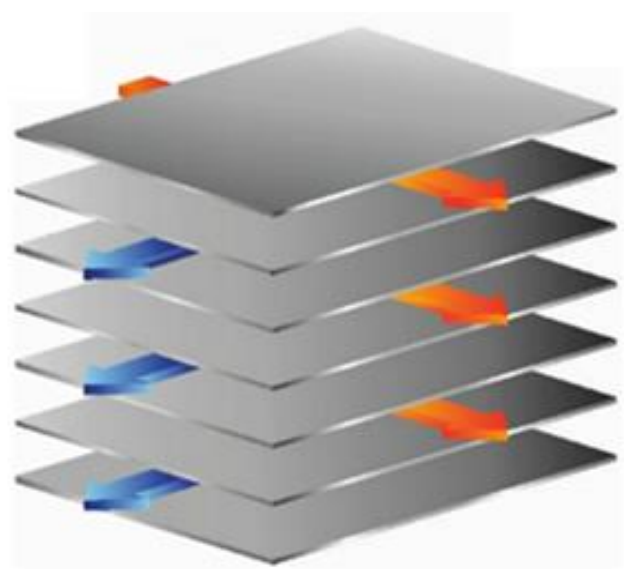

Fig 1. Plate HRV construction [5].

Mardiana et al [7] concluded that to study the performance of HRV in terms of heat duty and effectiveness, the following parameters should be considered: the dimensions which determine the core size, the core material, flow arrangement, airflow rate, and the permissible pressure drop.

Alireza Vali et. al [8] showed that the highest sensible effectiveness was obtained by using fins with a smaller aspect ratio. To achieve more than $60 \%$, effectiveness, NTU should be larger than 3 with an aspect ratio less. than 0.3 .

Ahmed A. Abduljabbar [9] showed that reducing the channel pitch of the core by increasing fin density acted as a motivation for better performance.

Ahmed Taha Al-Zubaidi [10] found that the effectiveness for corrugated fins was found $10 \%$ higher than the case of the pins type owing to the difference in surface area, passage length, and Reynolds number. The pressure drop in both cases was $11.02 \mathrm{~Pa}$.

Ranganayakulu and K.N. Seetharamu [11] concluded that the heat transfer coefficient of the gases is smaller than liquids by 10 to 50 times. Therefore, enhancing the air-side heat transfer coefficient could have significantly reduced the heat exchanger size. It was possible to achieve this target by increasing the heat transfer surface area per unit volume by adding fin.

\section{Theoretical Analysis}

A commercial HRV is analyzed under climate similar to the climate in Basra City. The technical feature of the HRV is shown in Table 1. The HRV configuration parameters, operating parameters, and assumptions are first determined. then the dominant equations and formulas are discussed.

Table 1. The technical features of the HRV unit [5].

\begin{tabular}{llll}
\hline Character & Value & Character & Value \\
\hline
\end{tabular}




\begin{tabular}{llll}
\hline $\mathrm{n},($ fin $/ \mathrm{m})$ & 0 & Heat Transfer area $(\mathrm{A})$ & $7.615 \mathrm{~m}^{2}$ \\
$\mathrm{a}$, (fin spacing) & -- & $\sigma=\left(\mathrm{A}_{\mathrm{o}} / \mathrm{A}_{\mathrm{fr}}\right)$ & $0.446 \mathrm{~m}^{2} / \mathrm{m}^{2}$ \\
$\mathrm{~b}$, (Plate spacing) & $5.1 \mathrm{~mm}$ & $\beta=\left(\mathrm{A} / \mathrm{V}_{\mathrm{p}}\right)$ & $390.2 \mathrm{~m}^{2} / \mathrm{m}^{3}$ \\
$N_{\text {plate }} /$ side & 28 & $\alpha=(\mathrm{A} / \mathrm{V})$ & $173.94 \mathrm{~m}^{2} / \mathrm{m}^{3}$ \\
Rated air flow & $1000 \mathrm{~m}^{3} / \mathrm{h}$ & $\mathrm{L}_{1} \times \mathrm{L}_{2} \times \mathrm{L}_{3}$ & $370 \times 370 \times 320 \mathrm{~mm}$ \\
\hline
\end{tabular}

\subsection{Geometrical analysis}

The compact air-to-air plate heat exchanger under investigation is shown in Fig 2. The exterior dimensions are L1, L2, and L3 as length, width, and depth respectively. Several plates are arranged to create adjacent overlaid cross-passage ways for air streams (both streams are unmixed).

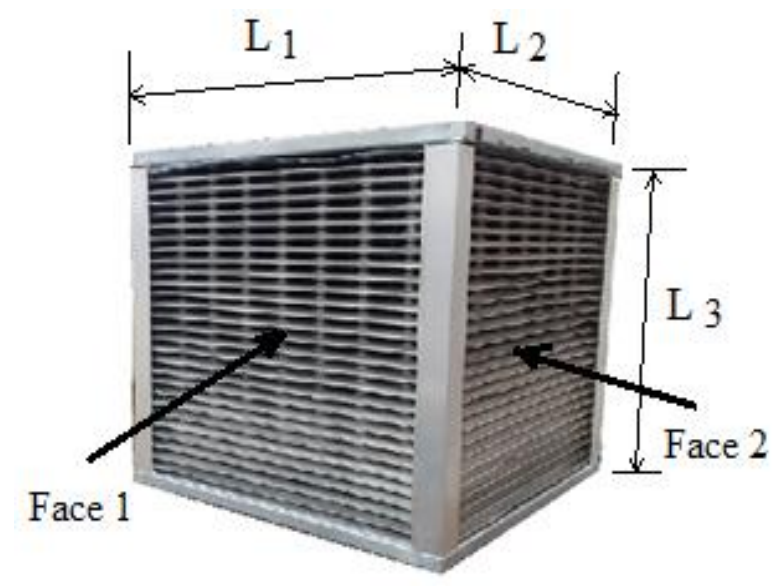

Fig 2. The core of the heat Recovery unit [5].

The specified data of the core is taken from Table 1 .

The primary heat transfer area is,

$A_{p}=\alpha V$

The minimum flow area through the core is,

$A_{o}=\sigma A_{f r}$

The frontal area of each flow side, $A_{f r}$

$A_{f r, i}=L_{i} L_{3}$, 
The mass flow rate of air $\dot{m}$ is calculated as

$\dot{m}=\rho \dot{V}$

The secondary heat transfer surface is provided through the fins area,

$A_{f}=2\left(b L_{j}\right) n L_{1} N_{\text {plate }}$,

The total heat transfer area for each flow face $A$ is given by,

$A=A_{p}+A_{f}$

The hydraulic diameter $D_{h}$ is given. by [12].

$D_{h}=4 \frac{A o}{\frac{A}{L_{j}}}$

$\left(\mathrm{A} / L_{j}\right)$ is the wetted perimeter.

The ratio of minimum free flow area to frontal area for each flow face $\boldsymbol{\sigma}$, is given by, $\sigma=\frac{A_{o}}{A_{f r}}$

The ratio of total surface area for a flow face relative to the void. volume is designated as $\beta$ and is given by,

$\beta=\frac{A}{V_{p}}$

The heat transfer surface area for one flow face divided by the total apparent volume $V$ of the exchanger is designated as $\alpha$,

$\alpha=\frac{A}{V}$

\subsection{Thermal analysis}

The analysis is based on a set of heat exchanger dimensions and a specified volume air flow rate $(\dot{V})$ at predetermined temperatures of entering both hot and cold airstreams, $T_{h, i}$ and $T_{c, i}$, respectively.

Assuming Steady. state heat transfer with no losses and the air is uniformly distributed. Air properties are evaluated in the first pass of calculation at the inlet. No condensation of moisture. The heat conductivity of the metal is constant.

The subscripts $c$ and $h$ denote cold and hot streams respectively, i and o denote inlet and outlet respectively.

The mass flow rate $(\dot{m})$ is expressed as,

$$
\dot{m}=\rho \dot{\mathrm{V}} / 3600(\mathrm{~kg} / \mathrm{s})
$$

$\dot{\mathrm{V}}$ is the air volume flow rate $\left(\mathrm{m}^{3 /} / \mathrm{h}\right)$

The heat capacity, $\mathrm{C}$ is, 
$C=\dot{m} c_{p} \quad(\mathrm{~W} / \mathrm{K})$

$C_{\min }$ is the smaller of $C_{h}$ and $C_{c}$.

The specific heat ratio is $\left(C^{*}\right)$;

$C^{*}=\frac{C_{\min }}{C_{\max }}$

The maximum velocity $\left(u_{\max }\right)$ through the minimum flow area,

$u_{\max }=\dot{m} / \rho A_{o} \quad(\mathrm{~m} / \mathrm{s})$

The mass velocity $\mathrm{G}$ is given by,

$G=\dot{m} / A_{o} \quad\left(\mathrm{~kg} / \mathrm{m}^{2} . \mathrm{S}\right)$

$R e$, is the Reynolds number,

$R e=\frac{\rho u_{\max } D_{h}}{\mu}$

A modified practical correlation of Nusselt number is used [5],

$N u=(0.93+0.0001 R e)\left[0.274 \operatorname{Re}^{0.569} \operatorname{Pr}^{0.333}\right]$

The heat transfer coefficient $h$ is given by,

$h=N u \frac{k}{D_{h}}$

The efficiency of thin fins is given as [12],

$\eta_{f}=\frac{\tanh \left(\sqrt{\frac{2 h}{k_{m} t_{f}}} l_{f}\right)}{\sqrt{\frac{2 h}{k_{m} t_{f}}} l_{f}}$

$k_{m}$ fin material thermal conductivity

$L_{f}$ the fin length

The overall heat transfer coefficient, assuming no fouling layers is given as [13].

$\frac{1}{U A}=\frac{1}{\left(\eta_{o} h A\right)_{c}}+\frac{t_{S h}}{k_{m} A_{p}}+\frac{1}{\left(\eta_{o} h A\right)_{h}}$

$\eta_{o}=1-\frac{A_{f}}{A}\left(1-\eta_{f}\right)$

The HRV effectiveness in terms of NTU is presented as, [14].

$\varepsilon=1-\exp \left[\left(\frac{N T U^{0.22}}{C^{*}}\right)\left\{\exp \left(-C^{*} N T U^{0.78}\right)-1\right\}\right]$ 
$N T U=\frac{U A}{C_{\min }}$

From the definition of the effectiveness $(\varepsilon)$, the recovered heat is obtained as,

$\dot{Q}=\varepsilon C_{\min }\left(T_{h, i}-T_{c, i}\right)$

Using the energy equation, the outlet temperature of the cold and hot streams can be determined as;

$T_{c, o}=T_{c, i}+\varepsilon \frac{C_{\min }}{C_{c}}\left(T_{h_{i}}-T_{c_{i}}\right)$

$T_{h, o}=T_{h, i}-\varepsilon \frac{c_{\min }}{C_{h}}\left(T_{h_{i}}-T_{c_{i}}\right)$

For the air to air heat cross-flow exchanger, since $C^{*} \approx 1$, the arithmetic average temperature is given [12].

$$
\begin{aligned}
& T_{m, h}=\frac{T_{h, i}+T_{h, o}}{2} \\
& T_{m, c}=\frac{T_{c, i}+T_{c, o}}{2}
\end{aligned}
$$

In this situation, it is necessary to recalculate the air properties and the thermal analysis steps have to be repeated based on the obtained mean air temperatures. If the resulting mean values of the mean temperature do not match the values of the last iterated, then the calculation should be repeated until they match.

\subsection{Hydraulic analysis}

The main pressure losses through the core only with uniform flow consist of:

- Contraction and Expansion losses at the entry and exit to the core.

- Friction losses along with the core [12].

$\Delta P=4 f\left(\frac{L}{D_{h}}\right)\left(\frac{G^{2}}{2 \rho}\right)+\left(K_{c}+K_{e}\right)\left(\frac{G^{2}}{2 \rho}\right)$

$K_{c}$ and $K_{e}$ are the entrance and exit loss coefficient.

The recommended values of $\mathrm{K}_{\mathrm{c}}$ and $\mathrm{K}_{\mathrm{e}}$ are given by [13],

$K_{c}=0.5(1-\sigma)$

$K_{e}=(1-\sigma)^{2}$

A modified practical correlation of friction factor is used [5],

$f=37.6523\left(\frac{l_{f}}{D_{h}}\right)^{-0.384}\left(\frac{a}{b}\right)^{-0.092} R e^{-0.835}$ 


\section{Results and discussions}

The analysis is conducted under the most frequent operating indoor air temperature $24^{\circ} \mathrm{C}$. The ranges of temperatures for outdoor weather are mostly ranged from $30^{\circ} \mathrm{C}$ to $48^{\circ} \mathrm{C}$ for hot climate in Basra. There are extremely hot and humid conditions, but they are considered rare and excluded.

Adding fins to the heat exchanger divides the air passages into smaller channels while increasing the surface area of the heat exchange. As a result, many factors are affected, some of which have a negative or positive impact to different extent on the HRV performance. Table 2 shows the effect of adding many fins up to 270 fins per $/ \mathrm{m}$. The flow rate is kept fixed at the maximum rated value of $1000 \mathrm{~m} 3 / \mathrm{h}$. The table demonstrates the change in most factors involved in the calculations of the performance. Relative comparison between the first case with no additional fins (row a), and the last case with $270 \mathrm{fin} / \mathrm{m}$ (row b). It is expected that an increase in the number of Reynolds will occur due to the decrease in the flow area $A_{o}$ after adding fins, but the calculations showed that Re is subjected to a decrease due to a greater percent reduction in the hydraulic diameter. This effect has reflected on the value of the Nusselt number $(\mathrm{Nu})$, which underwent some decrease. Nevertheless, the overall heat transfer coefficient (U) has increased due to the large increase in the surface area (A). The outcome of all these variables is an increase in the NTU value, which leads to an improvement in the effectiveness $(\varepsilon)$ when increasing the number of fins.

Table 2. Fin effect on the HRV performance.

\begin{tabular}{|c|c|c|c|c|c|c|c|c|c|c|}
\hline & $\mathrm{n}$ & $\mathrm{Nf}$ & A & Dh & $\mathrm{Re}, \mathrm{av}$ & Ao & $\mathrm{Nu}$ & U & NTU & $\varepsilon$ \\
\hline a & 0 & 0 & 7.62 & 0.0103 & 3248.4 & 0.0528 & 31.05 & 39.57 & 0.934 & 0.4556 \\
\hline \multirow{4}{*}{$1000 \mathrm{~m} 3 / \mathrm{h}$} & 54 & 20 & 9.5 & 0.008 & 2604.4 & 0.0511 & 25.975 & 42.58 & 1.25 & 0.5209 \\
\hline & 108 & 40 & 11.4 & 0.0064 & 2175.6 & 0.0494 & 22.604 & 45.87 & \begin{tabular}{|l|}
1.609 \\
\end{tabular} & 0.5745 \\
\hline & 143 & 53 & 13 & 0.0057 & 1969 & 0.048 & 20.97 & 48.1 & 1.86 & 0.603 \\
\hline & 162 & 60 & 13.2 & 0.0053 & 1868 & 0.0477 & 20.17 & 49.35 & \begin{tabular}{|l|}
2.013 \\
\end{tabular} & 0.6183 \\
\hline & 216 & 80 & 15.1 & 0.0045 & 1636.6 & 0.046 & 18.321 & 53.05 & 2.466 & 0.6541 \\
\hline b & 270 & 100 & 17 & 0.0039 & 1456.2 & 0.0443 & 16.86 & 56.96 & 2.972 & 0.6835 \\
\hline \multirow[t]{2}{*}{${ }^{*} 100 \%$ increase } & & & 1.23 & -0.6235 & -0.552 & -0.161 & -0.457 & 0.439 & 2.182 & 0.5003 \\
\hline & Th,i & Tc,i & Th,o & Tc,o & $\Delta T h$ & $\Delta \mathrm{Tc}$ & Qrec & $\Delta \mathrm{P}$ & $\beta$ & $\alpha$ \\
\hline a & 46 & 24 & 36 & 33.833 & 10.023 & 9.8326 & 3233.7 & 127.8 & 390.2 & 173.94 \\
\hline \multirow{5}{*}{$1000 \mathrm{~m} 3 / \mathrm{h}$} & 46 & 24 & 34.5 & 35.298 & 11.461 & 11.298 & 3706.5 & 240.9 & 502.1 & 216.92 \\
\hline & 46 & 24 & 33.4 & 36.508 & 12.639 & 12.508 & 4095.3 & 359.5 & \begin{tabular}{|l|}
621.7 \\
\end{tabular} & 259.61 \\
\hline & 46 & 24 & 33 & 37.166 & 13.28 & 13.17 & 4306 & 450 & 703 & 286.9 \\
\hline & 46 & 24 & 32.4 & 37.504 & 13.602 & 13.504 & 4414.1 & 507.1 & 750 & 302.31 \\
\hline & 46 & 24 & 31.6 & 38.323 & 14.39 & 14.323 & 4675.6 & 691.8 & \begin{tabular}{|l|}
887.8 \\
\end{tabular} & 345 \\
\hline b & 46 & 24 & 31 & 39 & 15.037 & 15 & 4891 & 922.7 & 1036 & 387.7 \\
\hline${ }^{*} 100 \%$ increase & & & & & 0.5003 & 0.5255 & 0.5125 & 6.221 & 1.656 & 1.2289 \\
\hline
\end{tabular}

One of the consequences of these variables is an increase in the amount of change in the temperature of hot and cold airstreams $\left(\Delta \mathrm{T}_{\mathrm{h}}\right.$ and $\left.\Delta \mathrm{T}_{\mathrm{c}}\right)$, which led to an increase in the amount 
of the recovered heat $\left(\mathrm{Q}_{\mathrm{rec}}\right)$. Although the exchanger kept its size, it became more compact by the substantial increase in values $\beta$ and $\alpha$. The only negative condition that accompanied the improvement in thermal performance is the increase in pressure drop $(\Delta \mathrm{P})$.

It is evident in Figs 3, 4, and 5 that adding fins causes an increasing ineffectiveness. The recovered heat and pressure drop are also increased. Adding up to $143 \mathrm{fins} / \mathrm{m}$ doses does not lead to exceeding the permissible pressure drop of $450 \mathrm{~Pa}$. At this point, the effectiveness is $60.3 \%$ instead of its initial value of $45.6 \%$ (an increase of 33.3\%). The recovered heat is increased by $34 \%$. Further, an increase in fins resulting in exceeding the permissible pressure drop. However, the number of fins can be increased to obtain better performance, but at a flow rate less than the maximum rate. For example, adding 162 and 216 to $270 \mathrm{fins} / \mathrm{m}$, the critical flow rates would be 904,695 , and $543.5 \mathrm{~m}^{3} / \mathrm{h}$ to obtain an efficiency of $62.3 \%, 67.2 \%$, and $71.1 \%$, respectively. Operating the HRV at flow rates less than the critical at any added number of fins does not set limits on the number of fins. The area under the red dashed line indicates the safe field in terms of pressure drop for any number of fins below $144 \mathrm{fin} / \mathrm{m}$. At a low flow rate with $270 \mathrm{fins} / \mathrm{m}$, the effectiveness reaches the threshold of $80 \%$.

Figs 6,7 , and 8 illustrate the effect of adding fins on the core volume relative to the original volume with no fins while maintaining its initial performance. The green point on the figures represents the exchanger condition at its original volume. It is clear from the figures that an increase in fins leads to an increase in all performance parameters. To keep these parameters unchanged, the volume of the exchanger should be reduced by a percent depends on the added number of fins. For example, when adding $20 \mathrm{fins} / \mathrm{m}$, the volume must be reduced to about $82.8 \%$ of its original size, noting that the pressure drop is still below or at the permissible limit. Also, adding 40 fins $/ \mathrm{m}$ allows reducing the size to $69 \%$ of the original without reservation.

The lowest volume that can be obtained without compromising the performance is $37 \%$ of the original volume by adding 120 fins $/ \mathrm{m}$. Extra fins do not lead to reduce the volume below $37 \%$ because it will lead to exceeding the maximum pressure drop. Adding 130 fins allows for a reduction in volume to $49 \%$, but with better performance, the effectiveness improved by $10.4 \%$, and the recovered heat increased by $11 \%$. Adding $143 \mathrm{fin} / \mathrm{m}$ does not allow for any reduction in the size. At this point, the HRV has its highest performance with an increase in effectiveness and recovered heat by $33.3 \%$ and $34 \%$ respectively. 


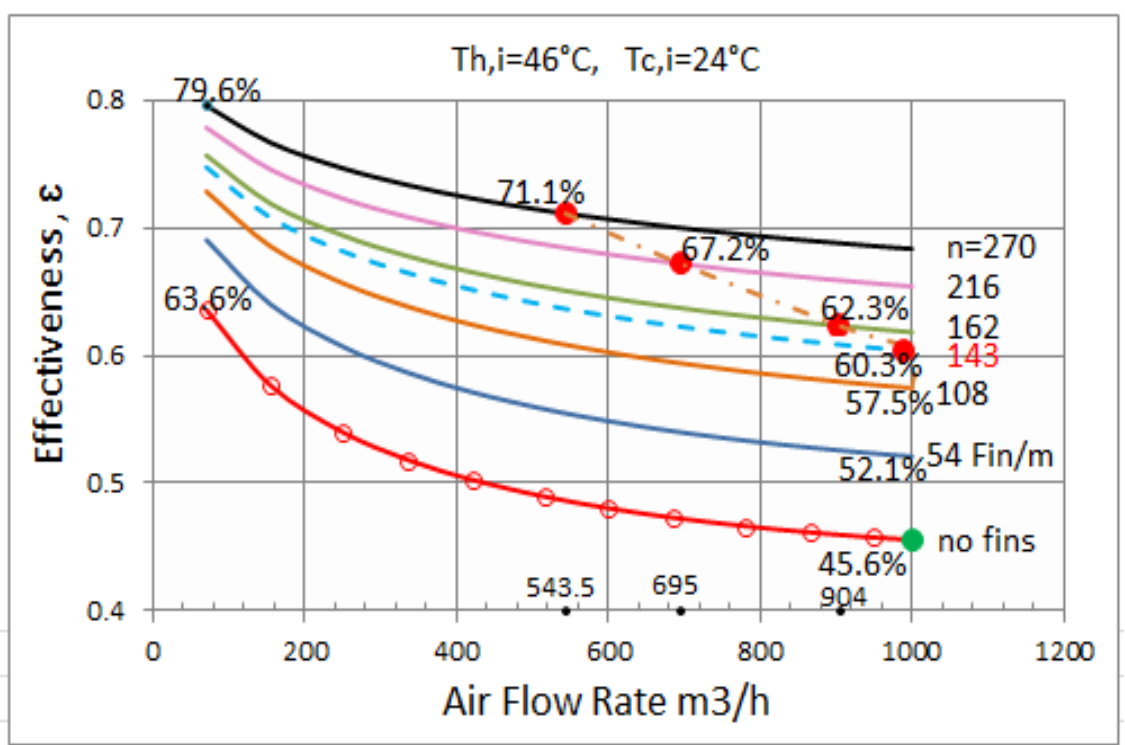

Fig 3. Effectiveness Vs flow rate.

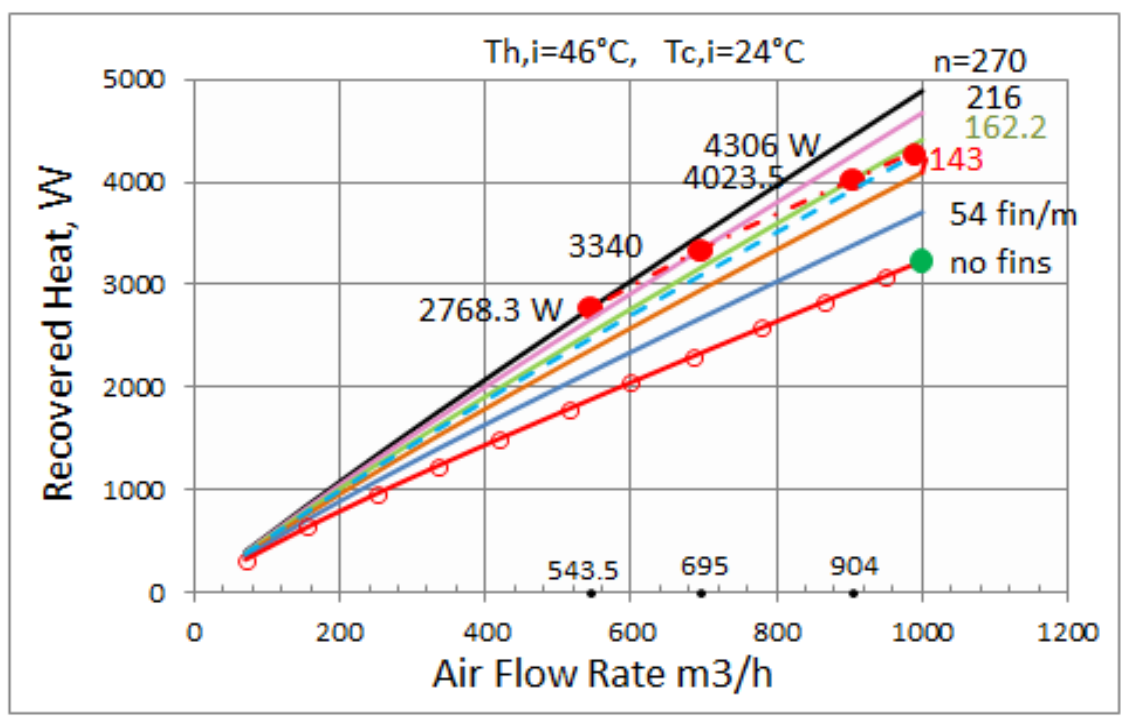

Fig 4. Recovered heat Vs flow rate. 


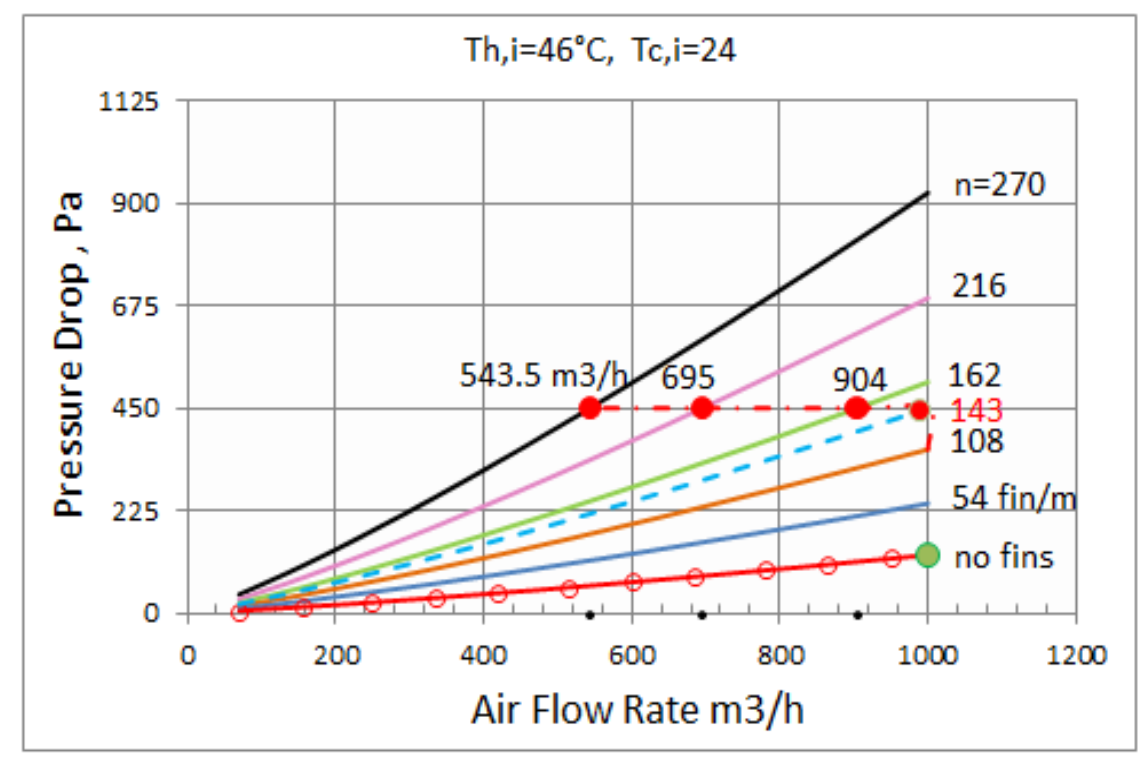

Fig 5. Pressure drupe Vs flow rate.

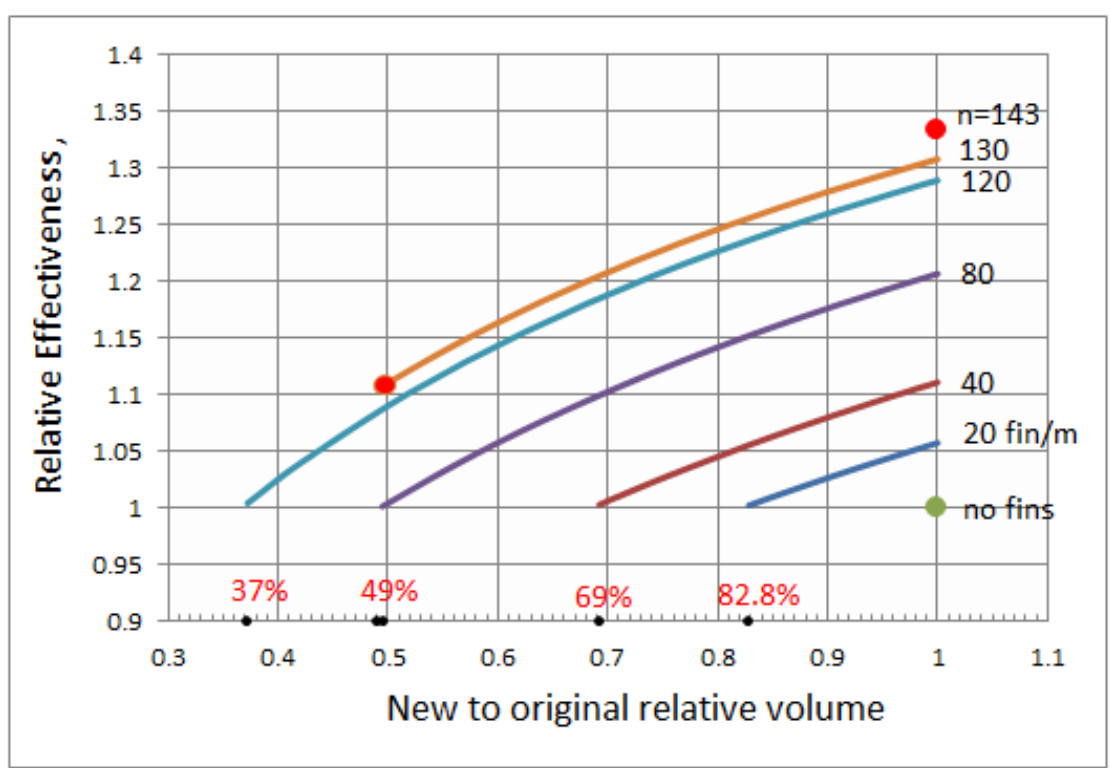

Fig 6. Effectiveness Vs relative volume. 


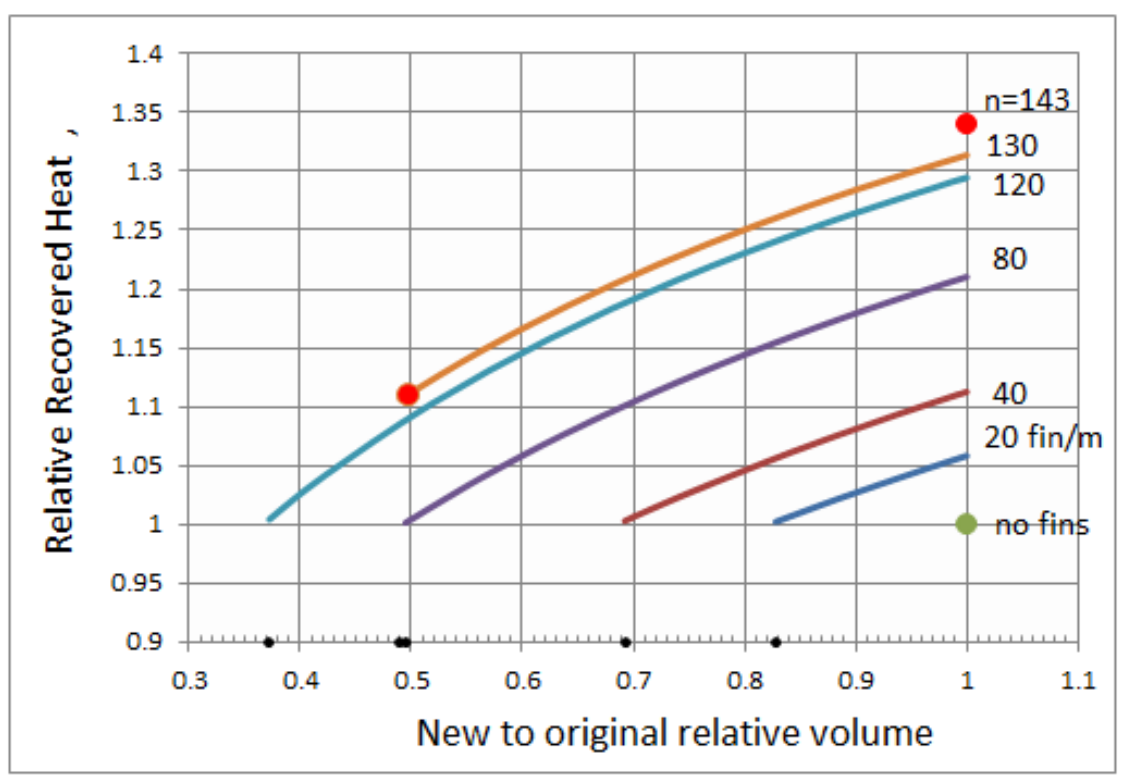

Fig 7. Recovered heat Vs relative volume.

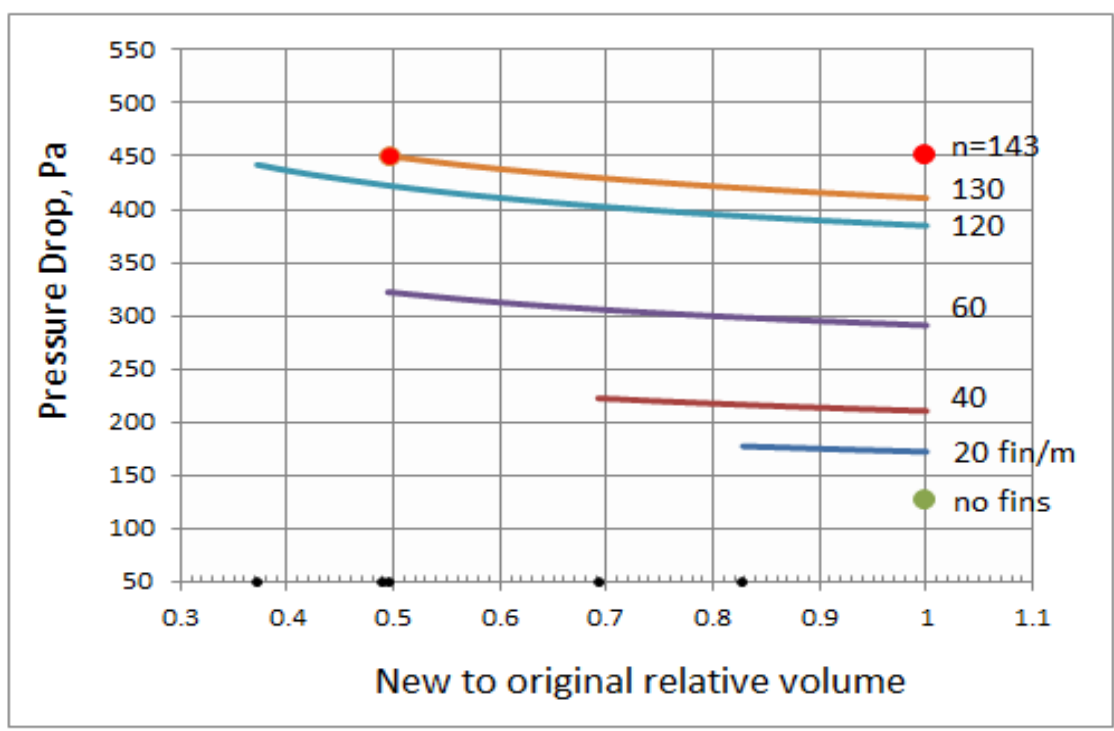

Fig. 8. Pressure drop Vs relative volume.

\section{Conclusions}

The following conclusions are extracted from the discussed results for the HRV performance: 
1- While the heat recovery ventilator recovers low-quality heat, it indirectly provides high-quality energy to accomplish the same task by A/C systems without violating the second law of thermodynamics.

2- The pressure drop did not exceed $130 \mathrm{~Pa}$ at its maximum rated design flow, allowing improving the thermal performance.

3- Adding fins up to $143 \mathrm{fin} / \mathrm{m}$, make the HRV has its highest performance with an increase in the effectiveness by $33.3 \%$ and an increase in the recovered heat by $34 \%$ with the condition of pressure drop not exceeding $450 \mathrm{~Pa}$.

4- The HRV size can be reduced to $37 \%$ of its original size without compromising its performance in terms of efficiency and heat duty by adding $120 \mathrm{fins} / \mathrm{m}$ with the condition of pressure drop not exceeding the permissible level.

\section{References}

[1]. Dominic O'Connor, John Kaiser. Calauti. "A Study of Passive Ventilation Integrated with Heat Recovery" Energy and Buildings, Volume 82, 2014.

[2]. Energy Efficiency In Canada, "Report to Parllament under the energy efficiency act 2017-2018" Energy Resource Canada.

[2]. Sidramappa Alur "Experimental Studies on Plate Fin-Heat-Exchangers". PhD thesis, Mechanical Engineering Department National Institute of Technology Rourkela 2012.

[4]. Ahmad Mardiana Idayu "Novel heat recovery systems for building applications" PhD thesis, University. of Nottingham 2011.

[5]. Braihan Abdulwadood Salman, "The Performance Evaluation of Energy Recovery Unit for Basra City" Master thesis in thermal technical engineering, Southern Technical University, Basra-Iraq 2020.

[6]. Ashrae-HVAC, fundamentals. Handbook 2001.

[7] Mardiana A. and S. B. Riffat, "Review on physical and performance parameters of heat recovery system for building applications" ELSEVIER, July 2013.

[8]. Alireza Vali, Carey J. Simonson, Robert. W. Besant, Gazi Mahmood "Numerical model and effectiveness correlations for a run-around heat recovery system with combined counter and cross flow exchangers" ELSEVIER, Journal of Heat and Mass Transfer 52 (2009) 5827-5840.

[9]. Ahmed. A. Abduljabbar "Energetic and Exergetic Study for Cross-Corrugated membrane-Based total Recovery Exchanger for Ventilation" PhD Thesis Cranfield University 2017

[10]. Ahmed Y Taha, Al-Zubaydi, Guang Hong and W. John Dartnall "CFD Modelling and Analysis of Different Plate-Heat Exchangers" ResearchGate 2017,

[11]. C. Ranganayakulu, K.N. Seetharamu "Compact Heat Exchangers-Analysis, Design and. Optimization using FEM and CFD approach" 2018 John Wiley \& Sons.

[12]. Ramesh K. Shah, Dusan P. Sekulic "Fundamentals of heat exchanger design", John Wiley \& Sons, Inc 2003.

[13]. J. P. Holman. "Heat Transfer" Tenth Edition, McGraw-Hill Series, 2010.

[14]. Eric M Smith "Advances in Thermal Design of Heat Exchangers, A Numerical Approach: Direct-

sizing, step-wise rating, and transients" John Wiley \& Sons, Ltd. 2005. 